\title{
Optical coherence tomography angiography evaluation of the effects of phacoemulsification cataract surgery on macular hemodynamics in Chinese normal eyes
}

\section{Xinyu Jia}

Tianjin Medical University

\section{Yinjuan Wei}

Tianjin Eye Hospital

Hui Song ( $\nabla$ songh221@hotmail.com )

Tianjin Medical University

\section{Research article}

Keywords: optical coherence tomography angiography, cataract, phacoemulsification, macular hemodynamics

Posted Date: November 20th, 2020

DOl: https://doi.org/10.21203/rs.2.23918/v3

License: (1) (1) This work is licensed under a Creative Commons Attribution 4.0 International License. Read Full License

Version of Record: A version of this preprint was published at International Ophthalmology on August 4th, 2021. See the published version at https://doi.org/10.1007/s10792-021-01987-8. 


\section{Abstract}

Background: To quantitatively evaluate the possible effects of phacoemulsification cataract surgery on macular hemodynamics using optical coherence tomography angiography (OCTA).

Methods: This was a prospective observational study. Superficial and deep macular vascular densities, as well as parameters of foveal avascular zone (FAZ), were measured preoperatively (baseline) and at 1 day, 1 week, and 4 weeks postoperatively in normal eyes ( $\geq 22 \mathrm{~mm}$ and $\leq 24 \mathrm{~mm}$ ) of patients scheduled for phacoemulsification cataract surgery with intraocular lens implantation. The correlations between the rate of change of pre- and post-operative vascular densities and surgical parameters were analyzed.

Results: A total of 123 eyes of 107 patients were included in this study. Compared to the baseline measurements, no statistically significant variation was found in macular vascular densities at 1 day after the surgery $(P>0.05)$. Both superficial and deep macular vascular densities were significantly increased postoperatively at weeks 1 and week $4(P<0.05 ; P<0.05)$, however no statistically significant differences were detected in any of the FAZ parameters between the baseline measurements and the entire follow-up period $(P>0.05$ for all). Also, no statistically significant correlations were established between main surgical parameters and macular vascular densities changes.

Conclusions: In normal eyes, macular blood perfusion gradually increased after phacoemulsification cataract surgery and was stabilized in one week. The foveal avascular zone was stabilized before and after the surgery. The main parameters and intraoperative perfusion of phacoemulsification surgery may not be the key factors affecting macular hemodynamics.

\section{Background}

The first phacoemulsifier was invented by Kelman in 1967. Based on the technological innovation during half a century, phacoemulsification cataract surgery with intraocular lens (IOL) implantation has become the most commonly used procedure for the treatment of cataract as a result of its small incision, short operation time, and rapid postoperative recovery. Surgeons use a maximum vacuum to reduce direct damage by the power of phacoemulsification, but it effectuates high perfusion pressure at the same time. This might cause transient intraocular pressure (IOP) fluctuations during surgery, resulting in corneal edema, poor visual acuity and longer time to recover after the surgery [1-2]. Whether the intraoperative perfusion and other surgical factors may cause fundus hemodynamic changes, especially macular microcirculation changes and then affect the patient's postoperative vision, needs further exploration. However, there have been only a few studies on this issue due to technical limitations [3-4]. Due to the limitations of these devices, there is yet no consistent conclusion [5-8]. Therefore, this study was designed to prospectively evaluate the hemodynamic changes of the macular microcirculation in patients before and after phacoemulsification cataract surgery using optical coherence tomography angiography (OCTA).

\section{Methods}

\subsection{Participants}


All subjects were from a Han Chinese population and recruited from Tianjin Eye Hospital (Tianjin, China) between May 5, 2019 and June 22, 2019. All participants were informed of the purpose of the research before obtaining and provided written informed consent for participation in the study. This prospective study was approved by the Ethical Review Committee of the Tianjin Eye Hospital and adhered to the provisions of the Declaration of Helsinki for research involving human subjects.

The sample size of this study was mainly determined by empirical methods [9-10]. All subjects underwent a comprehensive preoperative ophthalmological examination. Cataract severity was assessed using the Lens Opacities Classification System III (LOCS scale) [11]. Demographic information and medical history were recorded for all subjects, and their heart rates (HR), blood pressures (BP) and best-corrected visual acuity (BCVA) were measured before OCTA imaging. Subjects were included if they fulfilled the following criteria: patients diagnosed with age-related cataracts; age 60-70 years old; normal eyes ( $\geq 22 \mathrm{~mm}$ and $\leq 24 \mathrm{~mm}$ ) and normal IOP; LOCS-N: 2-3+. Exclusion criteria were as follows: patients with diabetes, hypertension and other systemic vascular disease; history of intraocular surgery or ocular trauma; history of laser treatment of the eye; history of high IOP or glaucoma; history of any fundus disease. In addition, patients with obvious postoperative anterior chamber inflammation or corneal edema under slit-lamp examination were also excluded.

A single experienced surgeon performed all the operations in the patients included in this study. Tropicamide eye drops (Santen Pharmaceutical Co., Ltd., Osaka, Japan) were used for mydriasis $30 \mathrm{~min}$ before the surgery, and cimetidine hydrochloride eye drops (Alcon, Fort Worth, TX, USA) were used for surface anesthesia. A 3.0-mm clear corneal tunnel incision was made above the temporal or nasal region of eyes with a scalpel. Continuous circular capsulorhexis was made, and nuclear hydrodissection was carried out. The lens was removed by phacoemulsification (Stellaris, Bausch \& Lomb Inc., Rochester, NY, USA) using a bottle with a height of $90 \mathrm{~cm}$. After polishing, IOLs were placed in the capsular bag and the incision was sealed. The effective phacoemulsification time (EPT) and cumulative dissipated energy (CDE) were noted at the end of each case based on the metrics of the phacoemulsification machine.

\subsection{OCTA image acquisition and data collection}

OCTA has emerged as a novel, rapid, non-invasive imaging modality that allows generating volumetric vascular images in seconds without any need to intravenously administer fluorescent dyes. It has broad applicability to retinal choroidal vascular disease and provides quantitative measurements of retinal vascular density [12-14]. Good reproducibility and repeatability of OCTA have been demonstrated on vascular and foveal avascular zone (FAZ) measurements [15-16]. The present study used the OCTA system (RTVue-XR; Optovue, Inc., Fremont, CA, USA) to detect blood flow. During the study, OCTA measurements were performed four times in each subject eye. The first measurement was performed one day before the cataract surgery (baseline), the second one day after the cataract surgery, and the last two were performed 1 and 4 weeks after the cataract surgery. To evaluate macular vessels, a $6 \mathrm{~mm} \times 6 \mathrm{~mm}$ scanning image centered on the macula was acquired and it was automatically divided into two segments, including the

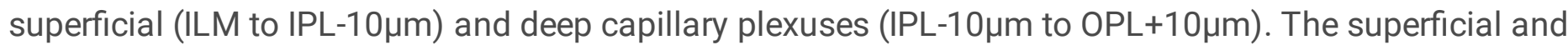
deep vascular densities (\%) were automatically quantified by the OCT machine' s inner software (version 
2014.2.0.93). The image were acquired and evaluated by two experienced researchers independently, and images with low quality (scan quality $<6$ ), and excessive artifacts were excluded. Subsequently, parameters including superficial and deep macular vascular densities of the whole image, FAZ area, FAZ perimeter (PERIM) and acircularity index (AI) were derived and recorded. The rate of change in vascular density was calculated by the difference in vascular density before and one day after the surgery, divided by preoperative blood vascular density (Figure 1).

\subsection{Statistical analysis}

SPSS (IBM, SPSS version 20.0; SPSS Inc, Chicago, IL, USA) was used for statistical analysis. The distribution of numerical variables was assessed by inspecting the histograms and using Shapiro-Wilk tests of normality. Qualitative data are expressed as frequency and numeric data are presented as the mean \pm standard deviation (SD). $\chi^{2}$ test was used for categorical variables. Repeated measures of variance analysis were used to compare the four-time repeated measurements. The correlation analysis was analyzed using Pearson's correlation analysis. $\mathrm{P}<0.05$ indicated statistically significance.

\section{Results}

A total of 6 eyes of the subjected in this study were excluded due to unclear optical media or poor fixation which conducted low quality scans. Finally, a total of 123 eyes of 107 patients were included in the study. The mean age of the patient cohort was $63.2 \pm 2.7$ years. The demographic and clinical characteristics of the subjects are summarized and compared in Table 1.

Vascular density is defined as the percentage of the area occupied by blood vessels in the en face image. The preoperative superficial and deep macular vascular densities were $45.29 \pm 4.06 \%$ and $44.15 \pm 5.67 \%$, respectively. The postoperative superficial macular vascular densities were $44.59 \pm 3.85 \%, 47.92 \pm 3.45 \%$, and $48.10 \pm 3.67 \%$, respectively. Moreover, the postoperative deep macular vascular densities were $43.12 \pm 6.13 \%$, $46.46 \pm 4.47 \%$, and $47.35 \pm 5.42 \%$, respectively. The findings indicated that macular vascular densities were altered significantly over time in the two layers (both $\mathrm{P}<0.05$ ). The minimum macular vascular densities were measured 1 day after the surgery. However, no significant difference was observed compared to the parameters before the surgery (both $P>0.05$ ). A marked increase was subsequently exhibited at weeks 1 and 4 (all $P<0.05)$. The trend of vascular density is shown in Figure 2.

The preoperative FAZ area, PERIM and AI were $0.35 \pm 0.13 \mathrm{~mm}^{2}, 2.25 \pm 0.46 \mathrm{~mm}$, and $1.14 \pm 0.02$, respectively. The postoperative FAZ area was $0.38 \pm 0.15 \mathrm{~mm}^{2}, 0.35 \pm 0.16 \mathrm{~mm}^{2}$ and $0.33 \pm 0.17 \mathrm{~mm}^{2}$ in the next three visits, respectively. The postoperative PERIM values were $2.34 \pm 0.59 \mathrm{~mm}, 2.17 \pm 0.59 \mathrm{~mm}$, and $2.12 \pm 0.58 \mathrm{~mm}$, respectively. And postoperative Al values were $1.12 \pm 0.61,1.10 \pm 0.26$, and $1.12 \pm 0.04$, No statistically significant differences were observed in any of the FAZ measurements for the entire study period $(P>0.05)$. The trend of FAZ parameters is shown in Figure 3.

Correlation analyses of the measurement parameters are presented in Tables 2 and 3 and Figure 4 . The rate of vascular density change was calculated based on the difference in vascular density before and one day after the surgery, divided by the preoperative blood vascular density. No statistically significant correlations 
were observed between EPT and the rate of change in both superficial and deep macular vascular densities or between $\mathrm{CDE}$ and the changes in macular vascular densities. No statistically significant correlations were established between postoperative BCVA and macular vascular densities (all $\mathrm{P}>0.05$ ).

\section{Discussion}

In this study, we performed a quantitative assessment of macular vascular density using OCTA and compared the macular blood perfusion before and after phacoemulsification cataract surgery in Chinese normal eyes. The patient's axial length, age, and IOP were limited to a small range, because these factors may affect the fundus blood flow [17]. Also, there was no statistical difference was detected in the blood pressure and heart rate of all patients during each examination. Notably, we found that the blood flow parameters in the macula area increased gradually and stabilized about one week after the surgery. FAZrelated parameters are stable before and after surgery. The main parameters of phacoemulsification surgery did not show any statistically significant correlations with changes in macular hemodynamics. Also, no statistically significant correlations were established between postoperative BCVA and macular vascular densities.

The inner retina was supplied by the central retinal vascular system and segmented into two layers on the OCTA image. One is the superficial capillary plexuses (SCP), mainly located in the retinal nerve fiber layer, including arterioles, venules, and capillaries. The other is the deep retinal vascular plexus (DCP), which is mainly located in the inner nuclear layer of the retina and consists of a capillary network $[12,13]$. Previous studies used OCTA, which indicated that fundus vessel density is negatively correlated with the axial length or age [18]. Abnormal vessel densities of SCP and DCP have been observed in the eyes or various systemic diseases, and the changes are often closely related to the decline of visual function [12囚19].

In this study, vascular densities in the macula area increased gradually from 1 day to 1 week after the surgery, which was consistent with the results of the study by Yu et al. [9]. The study used OCTA to investigate 13 cataract eyes and observed an increase in either perfusion or vessel density on SCP and DCP in a $3 \mathrm{~mm} \times 3 \mathrm{~mm}$ en face image one week after the surgery [9]. However, Yu et al. attributed this increase to the result of the different refractive media before and after the surgery, wherein the patients' ocular blood flow status was measured immediately after the surgical intervention, which ignored the impact of cataract surgery on macular hemodynamics. Moreover, Zhao et al. studied 32 cases of uncomplicated phacoemulsification surgeries by using OCTA [10]. A Significant increases was noted in macular vessel density and macular thickness were found at 1 and 3 months postoperatively. This phenomenon was basically consistent with the conclusions of our large-sample study. Previous studies have pointed out that fundus perfusion will eventually improves due to the IOP-lowering effect of cataract surgery, resulting from the widening of the anterior chamber [20-23]. This finding is consistent with the current study since patients' IOP decreased significantly at 1 week after the surgery. A previous study indicated that several inflammatory factors could be released due to the destruction of the blood-aqueous barrier, and many presented a vasodilator effect [24, 25]. The interpretation of these studies supports our findings. In addition, most of the subjects presented earlier cataracts (LOCS scale, median: N3, C4, P3) in the current study in order to ensure the imaging quality of larger en face images $(6 \mathrm{~mm} \times 6 \mathrm{~mm})$. The scan quality of all the included patients was 
$>6$ points, which was considered acceptable. We also manually excluded the images with good scan quality but more artifacts and speculated that the effect of lens opacities were diminished; thus, this study's results should be reliable.

Previous clinical studies of FAZ have many limitations due to the invasiveness, equipment complexity, and long scanning time of the method [26-29]. Some clinical studies using OCTA to analyze FAZ [30-34] were mainly focused on diabetic retinopathy(DR) and have shown a decrease in total retinal blood flow associated with an increase in FAZ area with increasing age $[35,36]$. These studies have also showed that the size of FAZ was negatively correlated to both the macular vascular density and BCVA [31, 37]. Therefore, FAZ parameters may detect the impairments of macular micro-vessels and visual function to some extent. In the current study, the influence of age has been avoided, and the FAZ area of the subjects after cataract surgery increased first, followed by a decrease; however, the differences were not significant $(P>0.05)$. This finding could be ascribed to the lack of systemic vascular disease in our participants. The postoperative microcirculation change was only transient and mild, with no qualitative vascular changes, which was consistent with the findings of Yu et al. [9], wherein no significant differences were detected in the FAZ area and perimeter between preoperative and measurements one week after cataract surgery. However, unlike our findings, Zhao et al. [10] found a decrease in the foveal avascular zone after cataract surgery in 32 patients with the axial length between $20 \mathrm{~mm}$ and $25 \mathrm{~mm}$. This difference may arise due to the inconsistency in the axial length of enrolled patients included in the two studies. Since the axial length is the influencing factor of fundus blood vessel density [3] and the eye volume is small in short eyes,the IOP fluctuation is rather severe in the surgery. In addition, fundus vessels are straight and fragile in long eyes and stretched due to eyeball extension [38]. Also, because of the large eye volume, the pressure on the eyeball wall is uneven during the operation [39].

The effects of various surgical parameters on ocular structures have been a primary concern and have been evaluated $[40,41]$. However, there is a dearth of literature on the effect of different flow parameters on the posterior segment. Previous studies [42] demonstrated that phacoemulsification ultrasound energy induces some cytokines, affecting ocular hemodynamics. This prompts us to explore the correlations between surgical parameters and changes in ocular blood flow. In this study, no statistically significant correlations were observed between the two parameters (EPT and CDE) and the rate of change in both superficial and deep macular vascular densities thereby suggesting that the main parameters of phacoemulsification surgery may not be the key factors affecting macular hemodynamics in normal eyes. The degree of intraoperative IOP increases and the unstable status of the intraocular fluid flow system could be the main influencing factor of macular hemodynamics [43-44]. However, the LOCS nuclear opalescence score of our subjects was mainly concentrated between $2+$ and $3+$, which might result in a very small fluctuation of the surgical parameter and reduce its influence. Also, the included patients did not present any vascular disease, and hence, the good vascular elasticity might cause a rapid recovery after surgery.

Previous studies on various ocular vascular diseases, such as retinal vein occlusion (RVO), DR, and macular telangiectasia, have demonstrated that the macular vascular densities are positively correlated with BCVA [18-19, 45]. However, in this study, no correlation was established between BCVA and macular vascular density at each follow-up after the surgery. This difference might be caused by the different vascular 
conditions of the included patients. Unlike the above studies, the physiological function of the fundus blood vessel in patients included in this study was intact and did not have organic changes. However, the effect of fundus vascular density on the visual function in patients after surgery needs further investigation

The main limitation of this study is the lack of research on patients with more severe cataracts. However, this study is the basis for exploring the effects of phacoemulsification on macular hemodynamics in different populations in the future. Future studies in the future are needed to focus on abnormal eyes, especially in high myopia, glaucoma, and systemic vascular disease. This will provide a reference for clinical practice. For example, a highly myopic patients, who have long eyes, weak eyeball wall, and liquefying vitreum, have significant intraoperative IOP fluctuations. The comparison of ocular vasculature changes between long eyes and normal eyes before and after the surgery can guide the clinicians to optimize surgical parameters and clinical medication further. This study can also form a basis for further studies of fundus hemodynamic changes after vacuum application in femtosecond laser-assisted cataract surgery.

\section{Conclusions}

In the current study, macular blood perfusion in normal eyes gradually rose from one day to one week after phacoemulsification cataract surgery and stabilized in one week. FAZ measurements were stable before and after the surgery. The main parameters and intraoperative perfusion of phacoemulsification surgery might not be the key factors affecting macular hemodynamics.

\section{Abbreviations}

OCTA Optical coherence tomography angiography

FAZ Foveal avascular zone

IOL intraocular lens

IOP Intraocular pressure

HR Heart rates

BP Blood pressures

BCVA Best-corrected visual acuity

EPT Effective phacoemulsification time

CDE Cumulative dissipated energy

ILM Inner nuclear layer

IPL Inner plexiform layer

OPL Outer plexiform layer 
PERIM FAZ perimeter

Al Acircularity index

MAP Mean arterial pressure

LOCS Lens opacities olassification system

SCP Superficial capillary plexuses

DCP Deep retinal vascular plexus

DR Diabetic retinopathy

RVO Retinal vein occlusion

\section{Declarations}

\subsection{Ethics approval and consent to participate}

This prospective observational study was approved by the ethics committee of Tianjin Eye Hospital, and written informed consent was obtained from all patients.

\subsection{Consent for publication}

Not applicable.

\subsection{Availability of data and materials}

The datasets used and/or analyzed during the current study are available from the corresponding author on reasonable request.

\subsection{Competing interests}

The authors declare that they have no competing interests.

\subsection{Funding}

No funding received.

\subsection{Authors' contributions}

Design of the study (XJ, YW); data collection (XJ, YW); statistical analysis (XJ, YW); drafting of the manuscript $(\mathrm{XJ})$; critical revision $(\mathrm{YW}, \mathrm{HS})$. All authors read and approved the manuscript to be published.

\subsection{Acknowledgements}

Not applicable. 


\section{Footnotes}

Xinyu Jia and Yingjuan Wei contributed equally to this work.

Xinyu Jia and Yingjuan Wei are co-first authors.

\section{References}

1. Solomon KD, Lorente R, Fanney D, Cionni RJ. Clinical study using a new phacoemulsification system with surgical intraocular pressure control. J Cataract Refract Surg. 2016 Apr;42(4):542-9.

2. Gonzalez-Salinas R, Garza-Leon M, Saenz-de-Viteri M, Solis-S JC, Gulias-Cañizo R, Quiroz-Mercado H. Comparison of cumulative dissipated energy delivered by active-fluidic pressure control phacoemulsification system versus gravity-fluidics. Int Ophthalmol. 2018 Oct;38(5):1907-1913.

3. Avila CP Jr, Bartsch DU, Bitner DG, et al. Retinal blood flow measurements in branch retinal vein occlusion using scanning laser Doppler flowmetry. Am J Ophthalmol. 1998 Nov;126(5):683-90.

4. Sugiyama T, Araie M, Riva CE, Cheng L, Mueller AJ, Karavellas MP, et al. Use of laser speckle flowgraphy in ocular blood flow research. Acta Ophthalmol. 2010 Nov;88(7):723-9.

5. Hilton EJ, Hosking SL, Gherghel D, Embleton S, Cunliffe IA. Beneficial effects of small-incision cataract surgery in patients demonstrating reduced ocular blood flow characteristics. Eye (Lond). 2005 Jun;19(6):670-5.

6. Spraul CW1, Amann J, Lang GE, Lang GK. Effect of cataract extraction with intraocular lens implantation on ocular haemodynamics. J Cataract Refract Surg. 1996 Oct;22(8):1091-6.

7. Rainer G1, Kiss B, Dallinger S, Menapace R, Findl O, Schmetterer K, et al. Effect of small incision cataract surgery on ocular blood flow in cataract patients. J Cataract Refract Surg. 1999 Jul;25(7):964-8.

8. Turk A, Mollamehmetoglu S, Imamoglu HI, Kola M, Erdol H, Akyol N. Effects of phacoemulsification surgery on ocular hemodynamics. Int J Ophthalmol. 2013 Aug 18;6(4):537-41.

9. Yu S, Frueh BE, Steinmair D, Ebneter A, Wolf S, Zinkernagel MS, et al. Cataract significantly influences quantitative measurements on swept-source optical coherence tomography angiography imaging. PLOS One. 2018 Oct 2;13(10): e0204501.

10. Zhao Z, Wen W, Jiang C, Lu Y. Changes in macular vasculature after uncomplicated phacoemulsification surgery: Optical coherence tomography

11. Chylack LT Jr., Wolfe JK, Singer D, Leske MC, Bullimore MA, Bailey IL, et al. The Lens Opacities Classification System III. The Longitudinal Study of Cataract Study Group. Arch Ophthalmol. 1993 Jun;111(6):831-6.

12. Spaide RF, Fujimoto JG, Waheed NK, Sadda SR, Staurenghi G. Optical coherence tomography angiography. Prog Retin Eye Res. 2018 May; 64:1-55.

13. Chalam KV, Sambhav K. Optical coherence tomography angiography in retinal diseases. J Ophthalmic Vis Res. 2016 Jan-Mar;11(1):84-92.

14. Kashani AH, Chen CL, Gahm JK, Zheng F, Richter GM, Rosenfeld PJ, et al. Optical coherence tomography angiography: A comprehensive review of current methods and clinical applications. Prog Retin Eye Res. 
2017 Sep; 60: 66-100.

15. Mihailovic N, Brand C, Lahme L, Schubert F, Bormann E, Eter N, et al. Repeatability, reproducibility and agreement of foveal avascular zone measurements using three different optical coherence tomography angiography devices. PLoS One. 2018 Oct 18;13(10):e0206045.

16. Lei J, Pei C, Wen C, Abdelfattah NS. Repeatability and Reproducibility of Quantification of Superficial Peri-papillary Capillaries by four Different Optical Coherence Tomography Angiography Devices. Sci Rep. 2018 Dec 14;8(1):17866.

17. Yang S, Zhou M, Lu B, Zhang P, Zhao J, Kang M, et al. Quantification of Macular Vascular Density Using Optical Coherence Tomography Angiography and Its Relationship with Retinal Thickness in Myopic Eyes of Young Adults. J Ophthalmol. 2017; 2017:1397179.

18. Nesper PL, Roberts PK, Onishi AC, Chai H, Liu L, Jampol LM, et al. Quantifying Microvascular Abnormalities With Increasing Severity of Diabetic Retinopathy Using Optical Coherence Tomography Angiography. Invest Ophthalmol Vis Sci, 2017 May 1;58(6):BIO307-BIO315.

19. Wakabayashi T, Sato T, Hara-ueno C, Fukushima Y, Sayanagi K, Shiraki N, et al. Retinal Microvasculature and Visual Acuity in Eyes With Branch Retinal Vein Occlusion: Imaging Analysis by Optical Coherence Tomography Angiography. Invest Ophthalmol Vis Sci, 2017Apr1;58(4): 2087-2094.

angiography study. J Cataract Refract Surg. 2018 Apr;44(4):453-458.

20. Yang $\mathrm{CH}$, Hung PT. Intraocular lens position and anterior chamber angle changes after cataract extraction in eyes with primary angle-closure glaucoma. J Cataract Refract Surg. 1997 Sep;23(7):110913.

21. Bhallil S, Andalloussi IB, Chraibi F, Daoudi K, Tahri H. Changes in intraocular pressure after clear corneal phacoemulsification in normal patients. Oman J Ophthalmol. 2009 Sep;2(3):111-3.

22. Huang G, Gonzalez E, Lee R, Chen YC, He M, Lin SC. Association of biometric factors with anterior phacoemulsification for cataract. J Cataract Refract Surg. 2012 Jan;38(1):108-16.

23. Plange N, Rennings C, Herr A, Weber A, Roessler GF, Mazinani BE, et al. Ocular pulse amplitude before and after cataract surgery. Curr Eye Res. 2012 Feb;37(2):115-9

24. Bhagat K, Hingorani AD, Palacios M, Charles IG, Vallance P. Cytokine-induced venodilatation in humans in vivo: eNOS masquerading as iNOS. Cardiovasc Res. 1999 Mar;41(3):754-64.

25. Xu H, Chen M, Forrester JV, Lois N. Cataract surgery induces retinal pro-inflammatory gene expression and protein secretion. Invest Ophthalmol Vis Sci. 2011 Jan 5;52(1):249-55.

26. Shin ES, Sorenson CM, Sheibani N. Diabetes and retinal vascular dysfunction. J Ophthalmic Vis Res. 2014 Jul-Sep;9(3):362-73.

27. Cheung N, Mitchell P, Wong TY. Diabetic retinopathy. Lancet. 2010 Jul 10;376(9735):124-36.

28. Massin P, Bandello F, Garweg JG, Hansen LL, Harding SP, Larsen M, et al. Safety and efficacy of ranibizumab in diabetic macular edema (RESOLVE Study): a 12-month, randomized, controlled, doublemasked, multicenter phase II study. Diabetes Care. 2010 Nov;33(11):2399-405. 
29. Ford JA, Elders A, Shyangdan D, Royle P, Waugh N. The relative clinical effectiveness of ranibizumab and bevacizumab in diabetic macular oedema: an indirect comparison in a systematic review. BMJ. 2012 Aug 13; 345: e5182.

30. Li Z, Alzogool M, Xiao J, Zhang S, Zeng P, Lan Y. Optical coherence tomography angiography findings of neurovascular changes in type 2 diabetes mellitus patients without clinical diabetic retinopathy. Acta Diabetol. 2018 Oct;55(10):1075-1082.

31. Samara WA, Shahlaee A, Adam MK, Khan MA, Chiang A, Maguire JI, et al. Quantification of Diabetic Macular Ischemia Using Optical Coherence Tomography Angiography and Its Relationship with Visual Acuity. Ophthalmology. 2017 Feb;124(2):235-244.

32. Sim DA, Keane PA, Zarranz-Ventura J, Fung S, Powner MB, Platteau E, et al.The effects of macular ischemia on visual acuity in diabetic retinopathy. Invest Ophthalmol Vis Sci. 2013 Mar 28;54(3):235360.

33. Mansour AM, Schachat A, Bodiford G, Haymond R. Foveal avascular zone in diabetes mellitus. Retina. 1993;13(2):125-8.

34. Conrath J, Giorgi R, Raccah D, Ridings B. Foveal avascular zone in diabetic retinopathy: quantitative vs qualitative assessment. Eye (Lond). 2005 Mar;19(3):322-6.

35. Yu J, Jiang C, Wang X, Zhu L, Gu R, Xu H, et al. Macular perfusion in healthy Chinese: an optical coherence tomography angiogram study. Invest Ophthalmol Vis Sci. 2015 May;56(5):3212-7.

36. Grunwald JE, Piltz J, Patel N, Bose S, Riva CE. Effect of aging on retinal macular microcirculation: a blue field simulation study. Invest Ophthalmol Vis Sci. 1993 Dec;34(13):3609-13.

37. Freiberg FJ, Pfau M, Wons J, Wirth MA, Becker MD, Michels S. Optical coherence tomography angiography of the foveal avascular zone in diabetic retinopathy. Graefes Arch Clin Exp Ophthalmol. 2016 Jun;254(6):1051-8.

38. Ng DS, Cheung CY, Luk FO, Mohamed S, Brelen ME, Yam JC, et al. Advances of optical coherence tomography in myopia and pathologic myopia. Eye (Lond) 2016;30:901-16.

39. Fan H, Chen HY, Ma HJ, Chang Z, Yin HQ, Ng DS, et al. Reduced Macular Vascular Density in Myopic Eyes. Chin Med J (Engl), 2017 Feb 20;130(4):445-451.

40. Baradaran-Rafii A, Rahmati-Kamel M, Eslani M, Kiavash V, Karimian F. Effect of hydrodynamic parameters on corneal endothelial cell loss after phacoemulsification. J Cataract Refract Surg. 2009 Apr;35(4):732-7.

41. Vasavada AR, Praveen MR, Vasavada VA, Vasavada VA, Raj SM, Asnani PK, et al. Impact of high and low aspiration parameters on postoperative outcomes of phacoemulsification: randomized clinical trial. J Cataract Refract Surg. 2010 Apr;36(4):588-93.

42. Wang N, Chintala SK, Fini ME, Schuman JS. Ultrasound activates the TM ELAM-1/IL-1/NF-kappaB response: a potential mechanism for intraocular pressure reduction after phacoemulsification. Invest Ophthalmol Vis Sci. 2003 May;44(5):1977-81.

43. Zhao Y, Li X, Tao A, Wang J, Lu F. Intraocular pressure and calculated diastolic ocular perfusion pressure during three simulated steps of phacoemulsification in vivo. Invest Ophthalmol Vis Sci. 2009 Jun;50(6):2927-31. 
44. Zhao YY, Chang PJ, Yu F, Zhao YE. Retinal vessel diameter changes induced by transient high perfusion pressure. Int J Ophthalmol. 2014 Aug 18;7(4):602-7.

45. Matet A, Daruich A, Dirani A, Ambresin A, Behar-Cohen F.. Macular Telangiectasia Type 1: Capillary Density and Microvascular Abnormalities Assessed by Optical Coherence Tomography Angiography. Am J Ophthalmol, 2016 Jul;167: 18-30.

\section{Tables}

Table 1. Demographic and clinical characteristics of the included patients.

\begin{tabular}{|c|c|c|}
\hline Parameters & Subclass & Numerical value \\
\hline \multirow[t]{2}{*}{ Gender, n (\%) } & Male & $45(42 \%)$ \\
\hline & Female & $62(58 \%)$ \\
\hline \multirow[t]{2}{*}{ Age, n (\%) } & $60<$ Age $\leqq 65$ & $52(49 \%)$ \\
\hline & $65<$ Age $\leqq 70$ & $55(51 \%)$ \\
\hline \multirow[t]{2}{*}{ Eye, n (\%) } & Right & $73(60 \%)$ \\
\hline & Left & $50(40 \%)$ \\
\hline \multirow[t]{2}{*}{ LOCS-N, n (\%) } & $2 \leqq$ nuclear $<3$ & $67(54 \%)$ \\
\hline & $3 \leqq$ nuclear $<4$ & $56(46 \%)$ \\
\hline \multirow[t]{4}{*}{ Intraocular pressure, IOP (mmHg)* } & Baseline & $15.3 \pm 4.2$ \\
\hline & 1 day post-operation & $14.5 \pm 3.9$ \\
\hline & 1 week post-operation & $12.0 \pm 3.1$ \\
\hline & 4 weeks post-operation & $12.6 \pm 3.3$ \\
\hline \multirow[t]{4}{*}{ Mean arterial pressure, $\mathrm{MAP}(\mathrm{mmHg}) *$} & Baseline & $91.7 \pm 12.4$ \\
\hline & 1 day post-operation & $93.1 \pm 11.2$ \\
\hline & 1 week post-operation & $91.1 \pm 11.8$ \\
\hline & 4 weeks post-operation & $92.3 \pm 9.5$ \\
\hline Heart rate, $\mathrm{HR}$ & Baseline & $75.6 \pm 10.5$ \\
\hline \multirow[t]{3}{*}{$($ beats/min) $*$} & 1 day post-operation & $76.3 \pm 9.7$ \\
\hline & 1 week post-operation & $74.1 \pm 12.3$ \\
\hline & 4 weeks post-operation & $74.6 \pm 11.4$ \\
\hline \multicolumn{2}{|c|}{ Pre-operative BCVA } & $.480 \pm .152$ \\
\hline
\end{tabular}


LOCS $=$ lens opacities classification system; $\mathrm{N}=$ nuclear; $\mathrm{BCVA}=$ best-corrected visual acuity;

*Repeated measures of variance analysis: IOP: Baseline/1 day $>1$ week/4 week; MAP: no statistical difference (all P>0.05); HR: No statistical difference (all $\mathrm{P}>0.05$ ).

Numerical data are presented as means \pm standard deviations where applicable.

Table 2 Correlations between the surgical parameters and changes in macular vascular densities

\begin{tabular}{ccccc}
\hline $\begin{array}{c}\text { Surgical } \\
\text { parameters }\end{array}$ & \multicolumn{2}{c}{$\begin{array}{c}\text { Rate of change in superficial macular } \\
\text { vascular density }\end{array}$} & \multicolumn{2}{c}{$\begin{array}{c}\text { Rate of change in deep macular } \\
\text { vascular density }\end{array}$} \\
\hline EPT & $\mathrm{r}$ & $\mathrm{P}$ & $\mathrm{r}$ & $\mathrm{P}$ \\
$\mathrm{CDE}$ & .008 & .960 & -.029 & .856 \\
\hline
\end{tabular}

$\mathrm{P}<0.05$ indicated statistically significance.

Table 3 Correlations between postoperative BCVA and macular vascular densities

\begin{tabular}{clll}
\hline Vascular density & \multicolumn{3}{c}{ BCVA } \\
\cline { 2 - 4 } & \multicolumn{1}{c}{1 day } & \multicolumn{1}{c}{1 week } & 4 weeks \\
\hline Superficial macular vascular & $\mathrm{P}=0.334 ;$ & $\mathrm{P}=0.955 ;$ & $\mathrm{P}=0.218 ;$ \\
density & $\mathrm{r}=0.171$ & $\mathrm{r}=0.010$ & $\mathrm{r}=0.250$ \\
Deep macular vascular density & $\mathrm{P}=0.653 ;$ & $\mathrm{P}=0.910 ;$ & $\mathrm{P}=0.458 ;$ \\
& $\mathrm{r}=0.080$ & $\mathrm{r}=0.019$ & $\mathrm{r}=0.152$ \\
\hline
\end{tabular}

$\mathrm{P}<0.05$ indicated statistically significance

Figures 

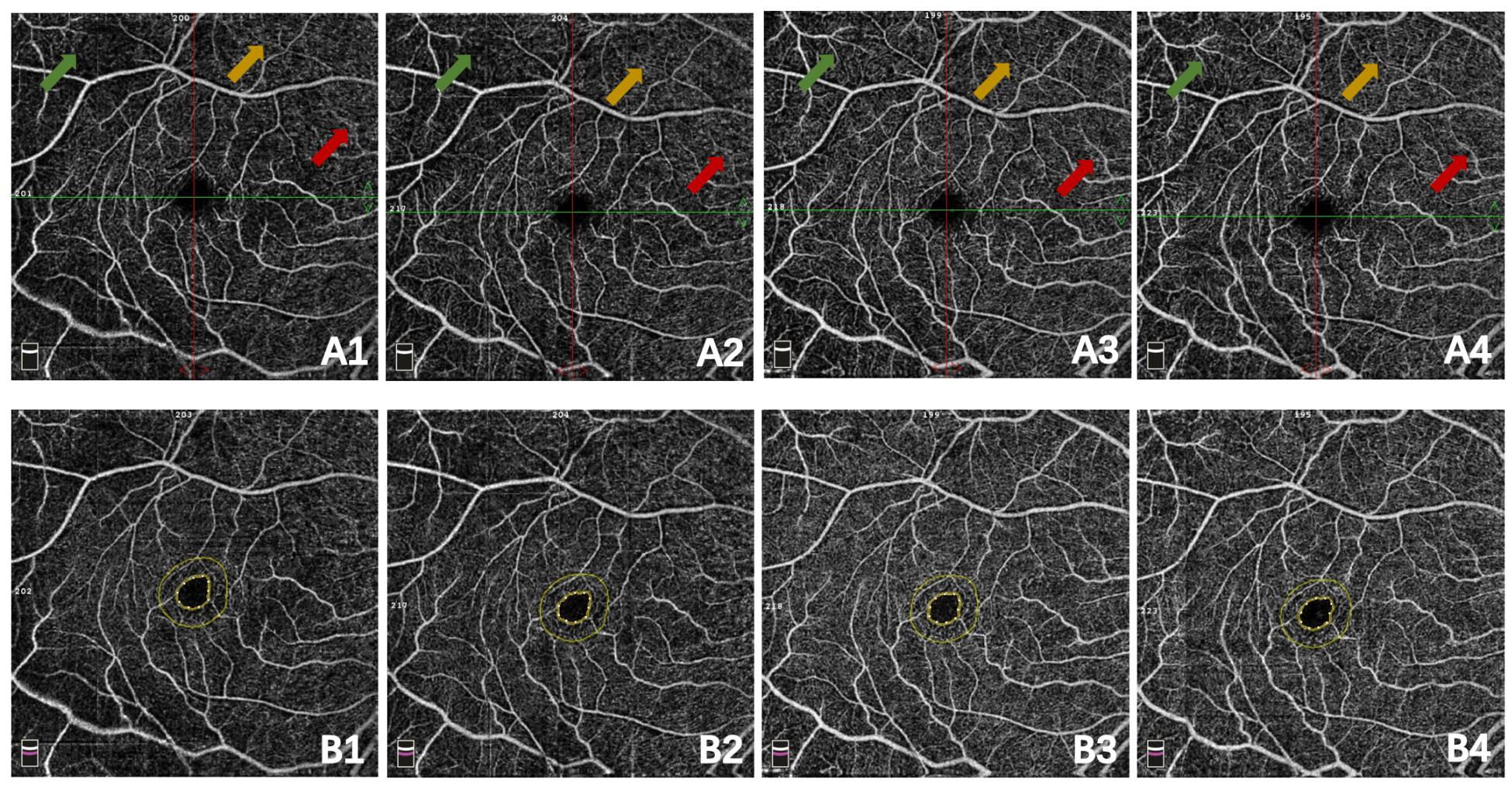

Figure 1

Vascular image (A) and FAZ circular band analysis image(B) in the OCTA enface image Figure 1 shows the follow-up results of the right eye of a patient aged 60-65 (LOCSIII: C3N2P3). A1-A4 corresponds to the macular vessel image before the surgery, one day after the surgery, one week after the surgery, and one month after the surgery, respectively. The vascular signals displayed in Figures A3 and A4 are significantly stronger than those in Figures A1 and A2. The areas indicated by the arrows can be used as examples. MOreover, the yellow rings in Figures B1-B4 correspond to FAZ images during the four visits. 
A

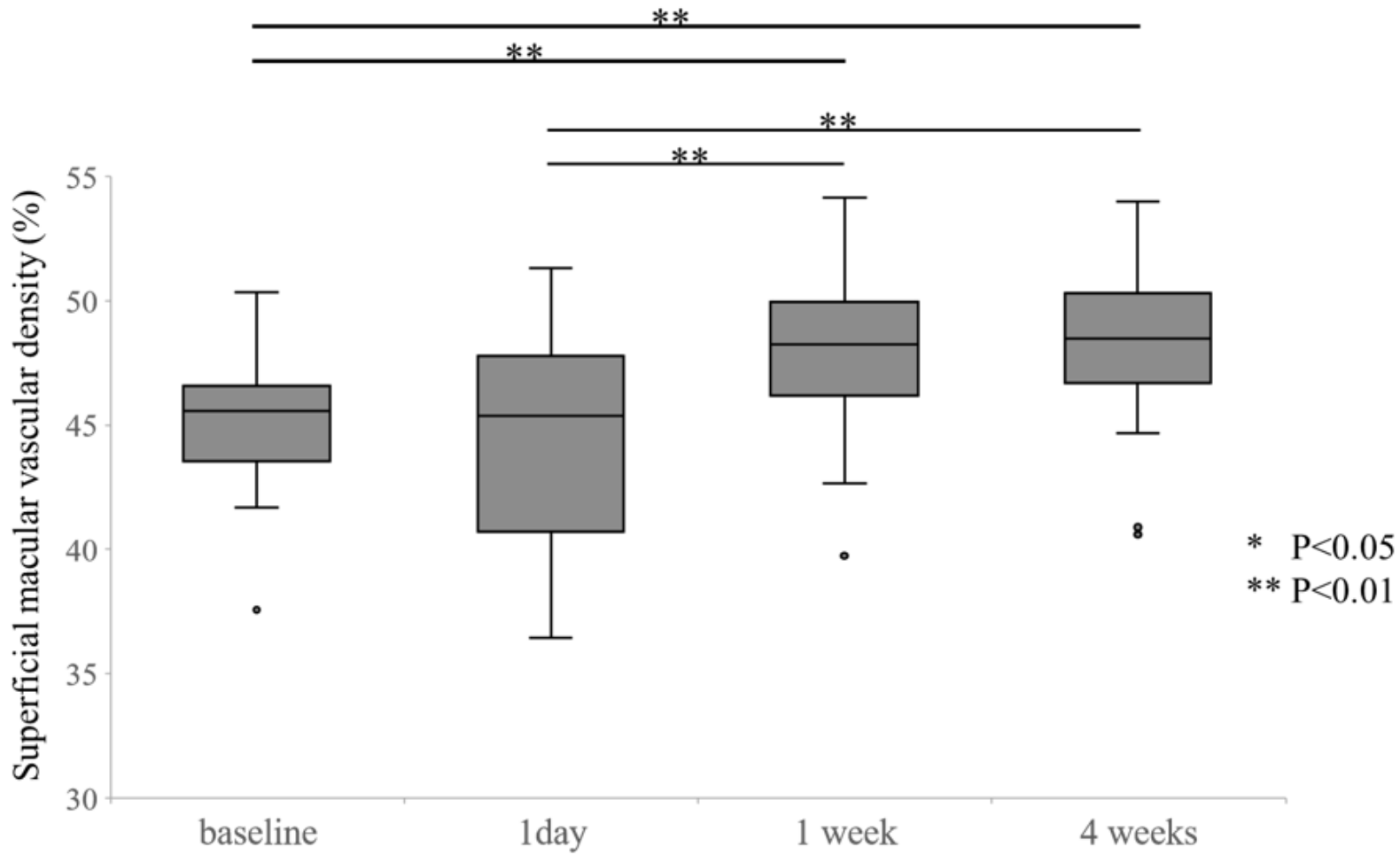

B

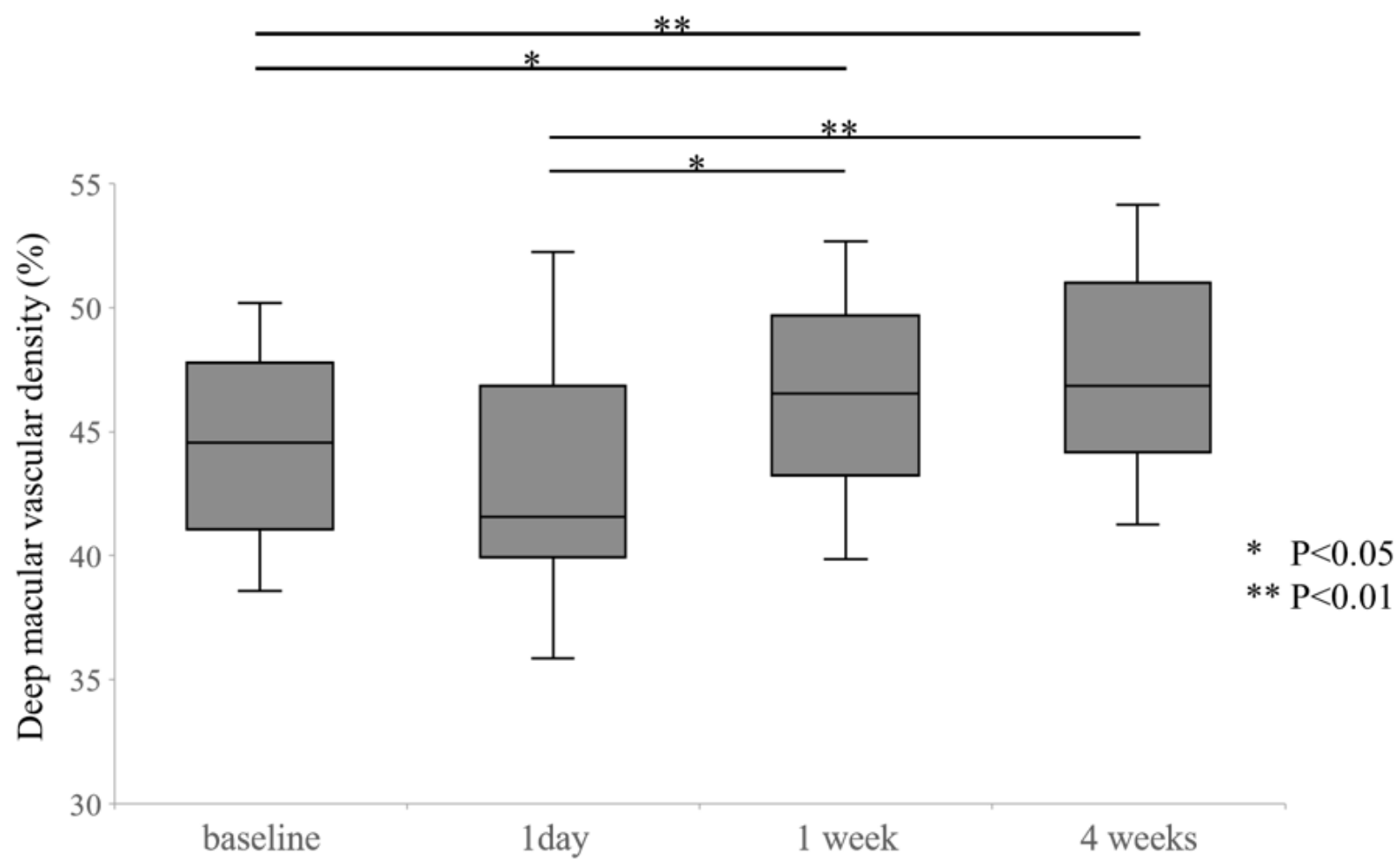

Figure 2

Macular vascular densities obtained at various time points in eyes undergoing phacoemulsification surgery. Figure 2 shows the changes in macular vascular density at different follow-up times. P-values were $<0.05$ when compared between groups. The remaining unlabeled P-values were $>0.05$. 

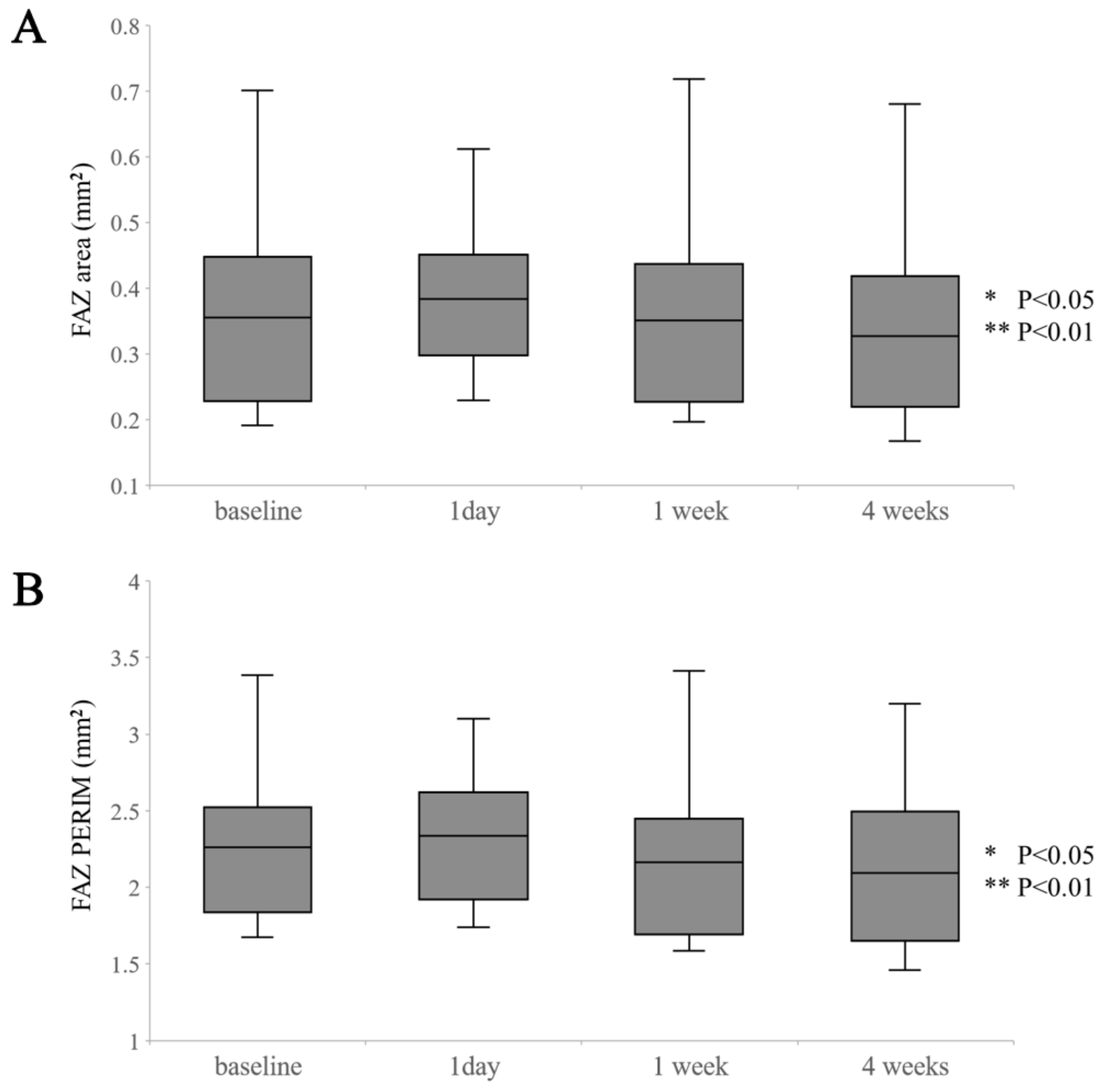

\section{Figure 3}

FAZ parameters obtained at various time points in eyes undergoing phacoemulsification surgery. Repeated variance analysis values did not reveal any significant difference in FAZ-related parameters measured at four follow-up visits $(P>0.05)$. 

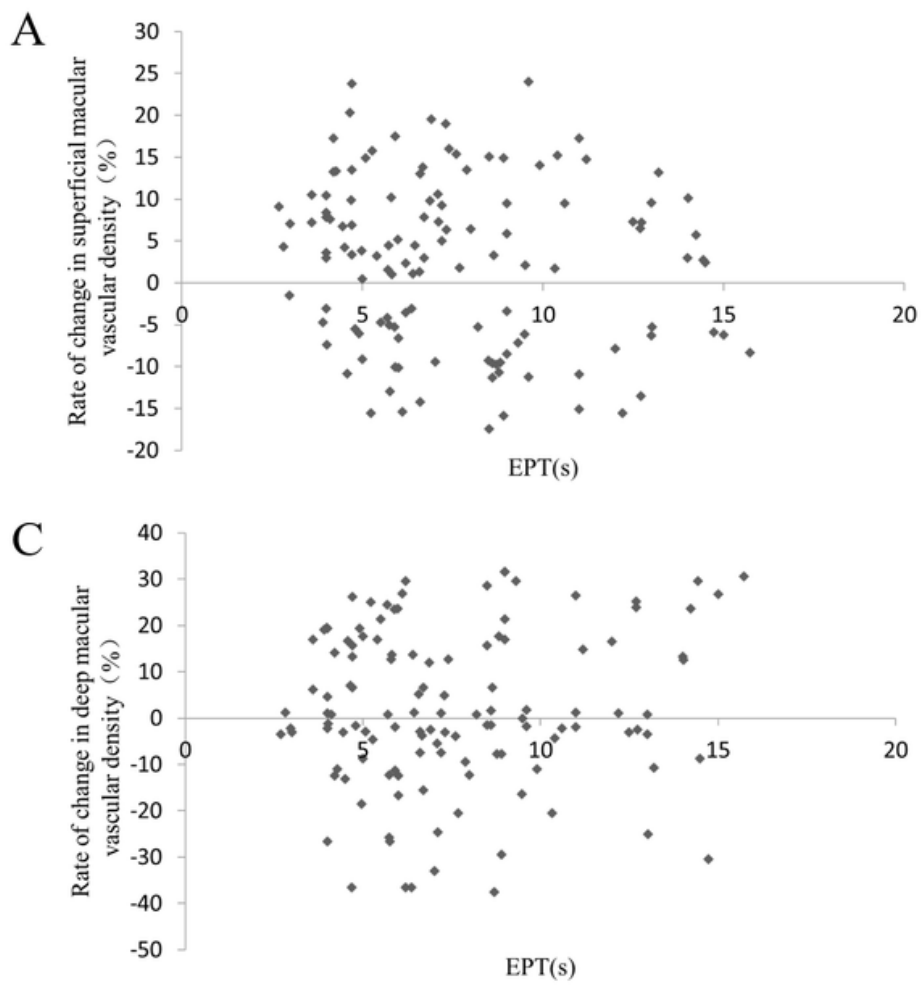

B

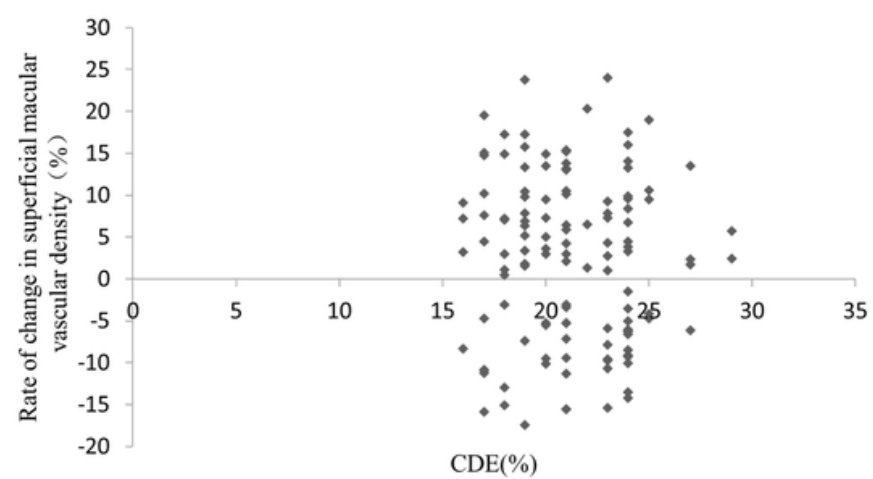

D

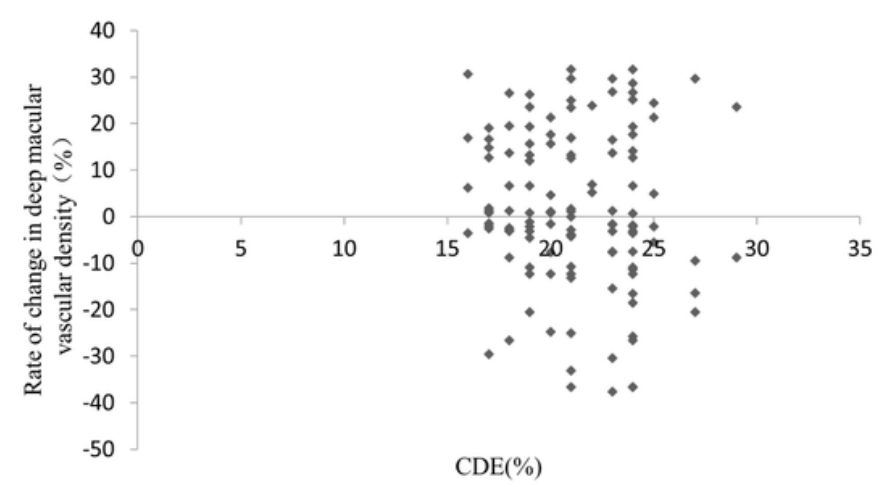

\section{Figure 4}

Correlatons between the surgical parameters and changes in macular vascular densities. No statistically significant correlations were established $(P>0.05)$.

\section{Supplementary Files}

This is a list of supplementary files associated with this preprint. Click to download.

- STROBEchecklist.pdf 